\title{
ANALISIS PRODUKTIVITAS TENAGA KERJA PADA PT. TUNGGAL PERKASA PLANTATIONS AIR MOLEK KABUPETEN INDRAGIRI HULU
}

\author{
Oleh: \\ Sry Windartini ${ }^{1)}$ Fitria Ningsih $^{2)}$ \\ ${ }^{1)}$ Program Studi Manajemen, Sekolah Tinggi Ilmu Ekonomi Indragiri (STIE-I) Rengat \\ Email: ikek@stieindragiri.ac.id \\ ${ }^{2)}$ Program Studi Manajemen, Sekolah Tinggi Ilmu Ekonomi Indragiri (STIE-I) Rengat \\ Email: fitrianingsih@stieindragiri.ac.id
}

\begin{abstract}
Background: The achievement of business objektives of the Organization the company due to cooperation between employees and the desire of the owner of the company to increase the employee's achievement. So the company has a bright prospect to the main terms of note is the development of employees ( the Existence of training ), the regulation of wages of employees, awarding the motivation of working to improve work produktivity. Problems that accur IE low granting compensation, the less pleasant working environment and a lack of motivation from the leadership. Objective : To Know the productivity of labor in PT. Might Singgle Plantations Air Molek Indragiri Hulu Regency. Methods : This research in the form of a descriptivate analysis based on literature and knowledge has been obtained by author. A large sample is taken by the method of random samplimg is random with the formula slovin 88 respondents. Results : The results shows that from the calculation of average yield = 3,89 which indicates overtime of employees at PT. Might Singgle Plantations Air Molek Indragiri Hulu Regency categorized "Hight" from the results obtained of average yield 3,95 which indicates that the motivator or motivation at PT. Might Singgle Plantations Air Molek Indragiri Hulu Regency categorized as "Good" from the calculation of average = 3, 97 which indicates that the increase in the result achieved employees at PT. Might Singgle Plantations Air Molek Indragiri Hulu Regency categorized as "Good" while the factors that cause the employees traying to increase work productivity with good result. Conclusion : Wages, Work Environment, Motivation and leadership plays an important role in increasing the productivity of the workforce. Work productivity can be measured from large or small products that are generated and the time it takes to complete the job.
\end{abstract}

Keywords : Produktivity, Motivation, Wages, Work Environment

\begin{abstract}
Abstrak
Latar Belakang : tercapainya tujuan organisasi perusahaan kerna adanya kerjasama antar karyawan dan keinginan dari pemilik perusahaan untuk meningkatkan prestasi kerja karyawan. Agar perusahaan mempunyai prospek cerah, syarat utama yang diperhatikan adalah mengembangkan karyawan (adanya pelatihan, peraturan upah karyawan, pemberian motivasi kerja untuk meningkatkan produktivitas kerja. Masalah yang terjadi diperusahaan yaitu rendahnya pemberian kompensasi, lingkungan kerja yang kurang menyenangkan dan kurangnya motivasi kerja dari pemimpin. Tujuan : Untuk mengetahui produktivitas tenaga kerja pada PT. Tunggal Perkasa Plantations Air Molek Kabupaten Indragiri HuLu. Metode : Penelitian ini berupa analisis deskriptif berdasarkan literatur dan pengetahuan yang telah penulis peroleh. Besar sampel diambil dengan metode random sampling secara acak dengan rumus slovin yaitu 88 responden. Hasil : Hasil penelitian menunjukkan bahwa hasil perhitungan rata-rata diperoleh $=3,39$ yang menunjukkan upah kerja lembur karyawan pada PT. Tunggal Perkasa Plantations Air Molek dikategorikan "Tinggi". Dari hasil perhitungan rata-rata diperoleh 3,95 yang menunjukkan bahwa motivator/motivasi pada PT. Tunggal Perkasa Plantations Air Molek dikategorikan "Baik". Dari perhitungan rata-rata =3,97 yang menunjukkan mengenai peningkatan hasil yang dicapai karyawan pada PT. Tunggal Perkasa Plantations Air Molek, dikategorikan "Baik" adapun faktor-faktor yang menyebabkan itu adalah karena karyawan berusaha untuk meningkatkan hasil produktivitas kerja dengan baik. Kesimpulan : Upah, lingkungan kerja, motivasi dan pimpinan berperan aktif dalam meningkatkan produktivitas tenaga kerja. Produktivitas kerja bisa diukur dari besar kecilnya produk yang dihasilkan dan waktu yang dibutuhkan untuk menyelesaikan pekerjaan.
\end{abstract}

Kata Kunci : Produktivitas Kerja, Motivasi, Upah, Lingkungan Kerja 


\section{PENDAHULUAN}

Tercapainya suatu tujuan organisasi perusahaan karena adanya kerja sama atau integritas antara para karyawan yang ada didalamnya, serta keinginan dari pemilik atau direksi organisasi perusahaan yang bersangkutan untuk mencapai tujuan tersebut, tentunya dengan melalui kegiatan yang dijalankan oleh orang lain (karyawan). Untuk mencapai tujuan perusahaan atau organisasi yang ditetapkan salah satu syarat adalah kecakapan karyawan dalam menyelesaikan masalah dibidang pekerjaan masing-masing sehingga dengan karyawannya yang terlatih akan lebih cepat mencapai sasaran yang di inginkan.

Untuk lebih kedepannya agar perusahaan mempunyai prospek cerah, maka masalah pengembangan karyawan merupakan masalah mendasar yang selalu mendapatkan prioritas perhatian bagi para pimpinan perusahaan. Dalam hal ini agar kualitas kerja karyawan semakin baik. Seseorang yang akan menempati suatu jabatan haruslah mendapatkan latihan-laatihan lebih dahulu, karena tanpa adanya latihan yang sesuai dengan tugas dan bidang kerja yang akan dihadapinya mustahil seorang karyawan akan dapat menempati posisi yang tepat. Dengan demikian bahwa proses pemberian latihan setiap karyawan yang akan menempati job tertentu merupakan persyarat yang utama yang perlu diperhatikan

Selain pengembangan dan pelatihan tenaga kerja serta menilai prestasi kerja yang ada, aspek lain yang secara lansung dapat berpengaruh terhadap kemajuan perusahaan yaitu masalah peraturan upah karyawan, karena merupakan struktur biaya yang selalu harus dianggarkan oleh setiap perusahaan dengan imbalan adanya input dari penjualan, sedangkan bagi para karyawan upah merupakan sumber kehidupan sehari-hari dengan kata lain adalah biaya bagi kelansungan hidup sehari-hari. Kondisi upah yang kurang memadai untuk memenuhi kebutuhan karyawan, sehingga menimbulkan kurangnya semangat dan gairah kerja karyawan ataupun hasil kerja kurang efisien sehingga produktivitas kerja menurun. Dalam hal ini perusahaan memandang perlu adanya pemberian motivasi kerja guna meningkatkan produktivitas kerja.

Setiap perusahaan mempunyai cara tersendiri dalam menetapkan pemberian upah terhadap karyawan agar dapat memberikan atau menunjang kehidupan yang lebih baik (layak), dengan demikian juga halnya dengan PT. Tunggal Perkasa Plantations Air Molek Kebupaten Indragiri Hulu, selalu berusaha mencari rumusan yang terbaik dalam rangka memberikan upah serta keperluan-keperluan lainnya kepada karyawannya, namun dalam hal ini banyak kendala-kendala diatasi secara baik, maka akan dapat menimbulkan kerugian pada perusahaan tersebut. Hal ini disebabkan karena masih rendahnya pemberian kompensasi, lingkungan kerja yang kurang menyenangkan serta kurangnya motivasi yang diberikan kepada setiap karyawan pada PT.Tunggal Perkasa Plantation Air Molek Kabupaten Indragiri Hulu. Berdasarakan uraian diatas, penulis melakukan penelitian dengan judul Analisis Produktivitas Tenaga Kerja Pada PT. Tunggal Perkasa Plantations Air Molek Kabupaten Indragiri Hulu.

\section{TINJAUAN PUSTAKA DAN HIPOTESIS}

a. Produktivitas Tenaga Kerja

Produktivitas adalah perbandingan antara hasil yang di capai dengan peran serta tenaga kerja persatuan waktu. Adanya kaitan antara hasil kerja dengan waktu yang dibutuhkan untuk menghasilkan produk dari seorang tenaga kerja. (Ravianto,2005:16)

Produktivitas juga di artikan sebagai kemampuan seperangkat sumber -sumber ekonomi untuk menghasilkan sesuatu atau diartikan juga sebagai perbandingan antara pengorbanan (input) dengan penghasilan (output), (suprihanto,2002:7).

Dari pendapat diatas dapat di simpulkan bahwa produktivitas tenaga kerja sangat tergantung pasa satuan masukan yang di berikan oleh tenaga kerja dan satuan luaran yang di hasilkan oleh tehaga kerja tersebut. Satuan masukan dan satuan keluaran pada produktivitas tenaga kerja hanya tenaga kerja itu sendiri dan hasilnya. 


\section{b. Tingkat Pendidikan}

Pendidikan adalah daya upaya yang memajukan timbulnya budi pekerti (kekuatan batin,karakter), pikiran(intelek) dan tumbuhnya anak untuk menjamin anak didik selaras dengan dunianya.(soemanto dan Soetopo,2002:11)

Tingkat pendidikan berupa pendidikan formal dan non formal mempunyai yujuan untuk mengembangkan kualitas sumber daya manusia yang terarah,terpadu dan menyeluruh melalui berbagai upaya proaktif dan reaktif dalam membentuk manusia seutuhnya agar manusia menjadi sadar akan dirinya dan dapat dimanfaatkan lingkungannya untuk meningkatkan taraf hidupnya. Produktivitas kerja memerlukan pengetahuan dan keterampilan dan penguasaan teknologi,sehinggadengan adanya tingkat pendidikan karyawan maka produktivitas kerja karyawan akan mudah tercapai.

c. Motivasi

Motivasi adalah keinginan seseorang yang mendorong untuk beraktivitas karena berharap akan membawa pada keadaan yang lebih memuaskan dari pada keadaan sekarang. Dengan motivasi orang akan terdorong untuk bekerja keras demi tercapainya tujuan yang diinginkanserta menggunakan keahlian dan kemampuan yang dimiliki untukmencapainya. (Gibson,2000:41).

Motivasi kerja adalah suatu faktor yang mendorong karyawan untuk melakukan tindakan tertentu yang mengarah pada suatu tujuan tertentu.(Deliarnov,2000:21).

Proses timbulnya motivasi dimana orang berusaha untuk mengetahui kebutuhankebutuhannya yang tidak terpenuhi,menyebabkan orang akan mencari jalan untuk mengurangi ketegangan yang disebabkan oleh kekurangankekuranganya.(suwarto,2001:33)

d. Upah

Upah adalah harga yang dibayarkan untuk suatu jenis kerja yang diberikan kepada seseorang karyawan pabrik,sedangkan gaji adalah bayaran yang diterima oleh pegawai kantor,staff ahli atau eksekutif,untuk suatu masa tertentu dan bahan berdasarkan jam kerja tertentu atau jumlah output tertentu.(Elizur,2004:6).

Sistem Pemberian upah yang baik adalah memenuhi syarat-syarat sebagai berikut (Ranupandojo,2001:32) :

1. Sederhana, sehingga mudah dimengerti

2. Adil, sesuai dengan prestasi yang tidak diuraikan

3. Bisa menutup biaya hidup

4. Mampu mendorong orang bekerja maksimum

e. Lingkungan Kerja

Lingkungan kerja menyangkut pemiliharaan antara berbagai alternatif usaha kegiatan yang akan datang bagi setiap unit yang berada dalam suatu organisasi secara keseluruhan. Untuk melaksanakan maksud tersebut diperlukan pemilihan dari tujuantujuan dan menentukan csrs pemcapaian.(Kontz\&Donnel,2005:125)

Lingkuangan kerja adalah segala sesuatu yang ada disekitar para pekerja dan dapat mempengaaruhi dirinya dalam menjalankan tugas-tugas yang dibebankan. Tiap-tiap tenaga kerja mendapat perlindungan atas keselamatan,kesehata,kesulitan,pemeliharaan moril manusia serta perlakuan yang sesuai dengan martabat manusia dan moral agama.(Nugroho,2006:4)

Dalam hal ini termasuk penerangan dan pewarnaan,kebersihan,teman kerja dalam perusahaan tersebut,dimana kita melakukan aktivitas untuk menghasilkan suatu produk yang dapat bermanfaat bagi kita semua. Kenyataannya lingkungan kerja dengan suasana menyenangkan adalah salah satu faktor terpeliharanya loyalitas tenaga kerja/karyawan. 
f. Kepemimpinan

Kepemimpinan adalah sebagai suatu seni dan ilmu memperoleh,memajukan dan memanfaatkan tenaga kerja,sehingga tujuan organisasi dapat teralisir secara daya guna sekaligus adanya kegairahan dari para pekerja.(Manullang,2003:14)

\section{HIPOTESIS PENELITIAN}

Dari permasalahan yang dihadapi perusahaan maka penulis mengemukakan hipotesa dalam penelitian ini adalah " Faktor-faktor yang mempengaruhi produktivitas tenaga kerja pada PT. Tunggal Perkasa Plantations Air Molek Kabupaten Indragiri Hulu.

\section{METODE PENELITIAN}

Penelitian yang penulis lakukan ini adalah beralamat di PT. Tunggal Perkasa Plantations Air Molek Kabupaten Indragiri Hulu.

Populasi dalam penelitian ini adalah seluruh Karyawan harian tetap yaitu sebanyak 726 orang, pada tahun ke 5 penelitian, sedangkan sampelnya sebanyak 88 orang serta teknik pengambilan sampel dengan menggunakan rumus Slovin, metode pengumpulan data menggunakan metode Random Sampling dan menggunakan analisa Deskriptif.

\section{HASIL DAN PEMBAHASAN}

\section{a. Upah Minimum}

Berikut akan dipaparkan jawaban Responden mengenai Upah Minimum Karyawan pada PT. Tunggal Perkasa Plantations Air Molek, seperti pada tabel 1 berikut ini :

Tabel 1 : Jawaban Responden mengenai Upah Minimum Karyawan pada PT. Tunggal Perkasa Plantations Air Molek

\begin{tabular}{|c|l|c|c|c|}
\hline No. & Kategori Jawaban & Bobot & Frekuensi & Nilai Bobot \\
\hline 1. & Sangat Tinggi & 5 & 29 & 145 \\
\hline 2. & Tinggi & 4 & 32 & 128 \\
\hline 3. & Cukup Tinggi & 3 & 26 & 78 \\
\hline 4. & Rendah & 2 & 1 & 2 \\
\hline 5. & Sangat Rendah & 1 & 0 & 0 \\
\hline \multicolumn{2}{r}{ Jumlah } & & 88 & 354 \\
\hline
\end{tabular}

Sumber : Data Olahan Hasil Penelitian, Tahun 2019

$$
\bar{x}=\frac{354}{88}=3,96
$$

Dari tabel di atas, dapat lihat jawaban responden mengenai Upah Minimum Karyawan pada PT. Tunggal Perkasa Plantations Air Molek Kabupaten Indragiri Hulu. Dari responden yang terdiri dari 88 orang yang menyatakan "Sangat Tinggi" sebanyak 29 orang atau dengan nilai bobot 145. Yang menyatakan "Tinggi" sebanyak 32 orang atau dengan nilai bobot 128. Yang menyatakan "Cukup Tinggi" sebanyak 26 orang atau dengan nilai bobot 78, sedangkan yang menyatakan "Rendah" sebanyak 1 orang atau dengan nilai bobot 2 dan yang menyatakan "Sangat Rendah" sebanyak 0 orang atau dengan nilai bobot 0 .

Dari hasil perhitungan rata-rata diperoleh $=3,96$ yang menunjukkan bahwa Upah Minimum Karyawan pada PT. Tunggal Perkasa Plantations Air Molek Kabupaten Indragiri Hulu, dikategorikan "Tinggi". Adapun faktor-faktor yang menyebabkan adalah karena Karyawan merasa puas dengan upah minimum yang diberikan. 


\section{b. Upah Kerja Lembur}

Berikut akan dipaparkan jawaban Responden mengenai Upah Kerja Lembur Karyawan pada PT. Tunggal Perkasa Plantations Air Molek Kabupaten Indragiri Hulu, seperti pada tabel 2 berikut ini :

Tabel 2: Jawaban Responden mengenai Upah Kerja Lembur Karyawan pada PT. Tunggal Perkasa Plantations Air Molek Kabupaten Indragiri Hulu

\begin{tabular}{|c|l|c|c|c|}
\hline No. & Kategori Jawaban & Bobot & Frekuensi & Nilai Bobot \\
\hline 1. & Sangat Tinggi & 5 & 26 & 130 \\
\hline 2. & Tinggi & 4 & 30 & 120 \\
\hline 3. & Cukup Tinggi & 3 & 28 & 84 \\
\hline 4. & Rendah & 2 & 4 & 8 \\
\hline 5. & Sangat Rendah & 1 & 0 & 0 \\
\hline \multicolumn{2}{|l}{ Jumlah } & & 88 & 342 \\
\hline
\end{tabular}

Sumber : Data Olahan Hasil Penelitian, Tahun 2019

$$
\bar{x}=\frac{342}{88}=3,89
$$

Dari tabel di atas, dapat lihat jawaban responden mengenai Upah Kerja Lembur Karyawan pada PT. Tunggal Perkasa Plantations Air Molek Kabupaten Indragiri Hulu. Dari responden yang terdiri dari 88 orang yang menyatakan "Sangat Tinggi" sebanyak 26 orang atau dengan nilai bobot 130. Yang menyatakan "Tinggi" sebanyak 30 orang atau dengan nilai bobot 120. Yang menyatakan "Cukup Tinggi" sebanyak 28 orang atau dengan nilai bobot 84 , sedangkan yang menyatakan "Rendah" sebanyak 4 orang atau dengan nilai bobot 8 dan yang menyatakan "Sangat Rendah" sebanyak 0 orang atau dengan nilai bobot 0 .

Dari hasil perhitungan rata-rata diperoleh $=3,89$ yang menunjukkan bahwa Upah Kerja Lembur Karyawan pada PT. Tunggal Perkasa Plantations Air Molek, dikategorikan "Tinggi". Adapun faktor-faktor yang menyebabkan adalah karena Perusahaan menetapkan upah kerja lembur sesuai dengan ketentuan yang ditetapkan Pemerintah.

\section{B. Analisis Lingkungan Kerja}

\section{a. Penerangan}

Adapun jawaban responden mengenai Penerangan dalam lingkungan kerja pada PT. Tunggal Perkasa Plantations Air Molek Kabupaten Indragiri Hulu, seperti pada tabel 3 di bawah ini :

Tabel 3: Jawaban Responden mengenai Penerangan dalam lingkungan kerja pada PT. Tunggal Perkasa Plantations Air Molek Kabupaten Indragiri Hulu.

\begin{tabular}{|c|l|c|c|c|}
\hline No. & Kategori Jawaban & Bobot & Frekuensi & Nilai Bobot \\
\hline 1. & Sangat Baik & 5 & 22 & 110 \\
\hline 2. & Baik & 4 & 40 & 160 \\
\hline 3. & Cukup Baik & 3 & 22 & 66 \\
\hline 4. & Tidak Baik & 2 & 3 & 6 \\
\hline 5. & Sangat Tidak Baik & 1 & 1 & 1 \\
\hline \multicolumn{2}{r}{ Jumlah } & & 88 & 343 \\
\hline
\end{tabular}

Sumber : Data Olahan Hasil Penelitian, Tahun 2019

$$
\bar{x}=\frac{343}{90}=3,90
$$

Dari tabel di atas, dapat lihat jawaban responden mengenai Penerangan dalam lingkungan kerja pada PT. Tunggal Perkasa Plantations Air Molek Kabupaten Indragiri Hulu. Dari responden yang terdiri dari 88 orang yang menyatakan "Sangat Baik" sebanyak 22 orang atau dengan nilai bobot 110. Yang menyatakan "Baik" sebanyak 40 
orang atau dengan nilai bobot 160. Yang menyatakan "Cukup Baik" sebanyak 22 orang atau dengan nilai bobot 66, sedangkan yang menyatakan "Tidak Baik" sebanyak 3 orang atau dengan nilai bobot 6 dan yang menyatakan "Sangat Tidak Baik" sebanyak 1 orang atau dengan nilai bobot 1 .

Dari hasil perhitungan rata-rata diperoleh $=3,90$ yang menunjukkan bahwa mengenai Penerangan dalam lingkungan kerja pada PT. Tunggal Perkasa Plantations Air Molek Kabupaten Indragiri Hulu, dikategorikan "Baik". Adapun faktor-faktor yang menyebabkan adalah karena tempat kerja sudah dilengkapi dengan fasilitas penerangan yang optimal.

\section{b. Suhu Udara}

Adapun jawaban responden terhadap mengenai suhu adara lingkungan kerja pada PT. Tunggal Perkasa Plantations Air Molek Kabupaten Indragiri Hulu, seperti pada tabel 4 di bawah ini :

Tabel 4: Jawaban Responden mengenai suhu udara lingkungan kerja pada PT. Tunggal Perkasa Plantations Air Molek Kabupaten Indragiri Hulu.

\begin{tabular}{|c|l|c|c|c|}
\hline No. & Kategori Jawaban & Bobot & Frekuensi & Nilai Bobot \\
\hline 1. & Sangat Baik & 5 & 23 & 115 \\
\hline 2. & Baik & 4 & 38 & 152 \\
\hline 3. & Cukup Baik & 3 & 24 & 72 \\
\hline 4. & Tidak Baik & 2 & 2 & 4 \\
\hline 5. & Sangat Tidak Baik & 1 & 1 & 1 \\
\hline \multicolumn{2}{r|}{ Jumlah } & & 90 & 344 \\
\hline
\end{tabular}

Sumber : Data Olahan Hasil Penelitian, Tahun 2019

$$
\bar{x}=\frac{344}{90}=3,91
$$

Dari tabel di atas, dapat lihat jawaban responden mengenai suhu udara lingkungan kerja pada PT. Tunggal Perkasa Plantations Air Molek Kabupaten Indragiri Hulu. Dari responden yang terdiri dari 88 orang yang menyatakan "Sangat Baik" sebanyak 23 orang atau dengan nilai bobot 115 . Yang menyatakan "Baik" sebanyak 38 orang atau dengan nilai bobot 152. Yang menyatakan "Cukup Baik" sebanyak 24 orang atau dengan nilai bobot 72, sedangkan yang menyatakan "Tidak Baik" sebanyak 2 orang atau dengan nilai bobot 4 dan yang menyatakan "Sangat Tidak Baik" sebanyak 1 orang atau dengan nilai bobot 1 .

Dari hasil perhitungan rata-rata diperoleh $=3,91$ yang menunjukkan bahwa mengenai suhu udara lingkungan kerja pada PT. Tunggal Perkasa Plantations Air Molek Kabupaten Indragiri Hulu, dikategorikan "Baik". Adapun faktor-faktor yang menyebabkan adalah karena suhu udara mendukung guna pencapaian kinerja Karyawan.

\section{Analisis Pimpinan}

\section{a. Motivator}

Adapun jawaban responden mengenai Motivator dalam mengarahkan Karyawan pada PT. Tunggal Perkasa Plantations Air Molek Kabupaten Indragiri Hulu, seperti pada tabel 5 di bawah ini : 
Tabel 5: Jawaban Responden mengenai Motivator dalam mengarahkan Karyawan pada PT. Tunggal Perkasa Plantations Air Molek Kabupaten Indragiri Hulu.

\begin{tabular}{|c|l|c|c|c|}
\hline No. & Kategori Jawaban & Bobot & Frekuensi & Nilai Bobot \\
\hline 1. & Sangat Baik & 5 & 23 & 115 \\
\hline 2. & Baik & 4 & 40 & 160 \\
\hline 3. & Cukup Baik & 3 & 23 & 69 \\
\hline 4. & Tidak Baik & 2 & 2 & 4 \\
\hline 5. & Sangat Tidak Baik & 1 & 0 & 0 \\
\hline \multicolumn{2}{r|}{ Jumlah } & & 88 & 348 \\
\hline
\end{tabular}

Sumber : Data Olahan Hasil Penelitian, Tahun 2019

$$
\bar{x}=\frac{348}{88}=3,95
$$

Dari tabel di atas, dapat lihat jawaban responden mengenai Motivator dalam mengarahkan Karyawan pada PT. Tunggal Perkasa Plantations Air Molek Kabupaten Indragiri Hulu. Dari responden yang terdiri dari 88 orang yang menyatakan "Sangat Baik" sebanyak 23 orang atau dengan nilai bobot 115. Yang menyatakan "Baik" sebanyak 40 orang atau dengan nilai bobot 160 Yang menyatakan "Cukup Baik" sebanyak 23 orang atau dengan nilai bobot 66, sedangkan yang menyatakan "Tidak Baik" sebanyak 2 orang atau dengan nilai bobot 4 dan yang menyatakan "Sangat Tidak Baik" sebanyak 0 orang atau dengan nilai bobot 0 .

Dari hasil perhitungan rata-rata diperoleh $=3,95$ yang menunjukkan bahwa mengenai Motivator dalam mengarahkan Karyawan pada PT. Tunggal Perkasa Plantations Air Molek Kabupaten Indragiri Hulu, dikategorikan "Baik". Adapun faktorfaktor yang menyebabkan adalah Pimpinan berusaha memberikan semangat kepada setiap Karyawan dalam mencapai produktivitas kerja.

\section{b. Menciptakan Lingkungan Kerja yang Baik}

Adapun jawaban responden mengenai Pimpinan menciptakan lingkungan kerja yang baik pada PT. Tunggal Perkasa Plantations Air Molek Kabupaten Indragiri Hulu, seperti pada tabel 6 di bawah ini :

Tabel 6: Jawaban Responden mengenai Pimpinan menciptakan lingkungan kerja yang baik pada PT. Tunggal Perkasa Plantations Air Molek Kabupaten Indagiri Hulu

\begin{tabular}{|c|l|c|c|c|}
\hline No. & Kategori Jawaban & Bobot & Frekuensi & Nilai Bobot \\
\hline 1. & Sangat Baik & 5 & 25 & 125 \\
\hline 2. & Baik & 4 & 34 & 136 \\
\hline 3. & Cukup Baik & 3 & 26 & 78 \\
\hline 4. & Tidak Baik & 2 & 3 & 6 \\
\hline 5. & Sangat Tidak Baik & 1 & 0 & 0 \\
\hline \multicolumn{2}{r}{ Jumlah } & & 88 & 345 \\
\hline
\end{tabular}

Sumber : Data Olahan Hasil Penelitian, Tahun 2019

$$
\bar{x}=\frac{345}{88}=3,92
$$

Dari tabel di atas, dapat lihat jawaban responden mengenai Pimpinan menciptakan lingkungan kerja yang baik pada PT. Tunggal Perkasa Plantations Air Molek. Dari responden yang terdiri dari 88 orang yang menyatakan "Sangat Baik" sebanyak 25 orang atau dengan nilai bobot 125 . Yang menyatakan "Baik" sebanyak 34 orang atau dengan nilai bobot 136. Yang menyatakan "Cukup Baik" sebanyak 26 orang atau dengan nilai bobot 78, sedangkan yang menyatakan "Tidak Baik" sebanyak 3 orang atau dengan nilai bobot 6 dan yang menyatakan "Sangat Tidak Baik" sebanyak 0 orang atau dengan nilai bobot 0 . 
Dari hasil perhitungan rata-rata diperoleh $=3,92$ yang menunjukkan bahwa Pimpinan menciptakan lingkungan kerja yang baik pada PT. Tunggal Perkasa Plantations Air Molek, dikategorikan "Baik". Adapun faktor-faktor yang menyebabkan adalah karena berusaha untuk memberikan kepuasan kepada Karyawan.

\section{Analisis Produktivitas}

\section{a. Kemampuan}

Adapun jawaban responden mengenai kemampuan Karyawan dalam melaksanakan pekerjaan pada PT. Tunggal Perkasa Plantations Air Molek, seperti pada tabel 7 di bawah ini :

Tabel 7: Jawaban Responden mengenai kemampuan Karyawan dalam melaksanakan pekerjaan pada PT. Tunggal Perkasa Plantations Air Molek Kabupaten Indragiri Hulu

\begin{tabular}{|c|l|c|c|c|}
\hline No. & Kategori Jawaban & Bobot & Frekuensi & Nilai Bobot \\
\hline 1. & Sangat Baik & 5 & 26 & 130 \\
\hline 2. & Baik & 4 & 32 & 128 \\
\hline 3. & Cukup Baik & 3 & 28 & 84 \\
\hline 4. & Tidak Baik & 2 & 1 & 2 \\
\hline 5. & Sangat Tidak Baik & 1 & 1 & 1 \\
\hline \multicolumn{2}{|l}{ Jumlah } & & 88 & 352 \\
\hline
\end{tabular}

Sumber : Data Olahan Hasil Penelitian, Tahun 2019

$$
\bar{x}=\frac{352}{88}=3,91
$$

Dari tabel 10 di atas, dapat lihat jawaban responden mengenai kemampuan Karyawan dalam melaksanakan pekerjaan pada PT. Tunggal Perkasa Plantations Air Molek Kabupaten Indragiri Hulu. Dari responden yang terdiri dari 88 orang yang menyatakan "Sangat Baik" sebanyak 26 orang atau dengan nilai bobot 130. Yang menyatakan "Baik" sebanyak 32 orang atau dengan nilai bobot 128. Yang menyatakan "cukup Baik" sebanyak 28 orang atau dengan nilai bobot 84 , sedangkan yang menyatakan "Tidak Baik" sebanyak 1 orang atau dengan nilai bobot 2 dan yang menyatakan "Sangat Tidak Baik" sebanyak 1 orang atau dengan nilai bobot 1 .

Dari hasil perhitungan rata-rata diperoleh $=3,91$ yang menunjukkan bahwa mengenai kemampuan Karyawan dalam melaksanakan pekerjaan pada PT. Tunggal Perkasa Plantations Air Molek Kabupaten Indragiri Hulu, dikategorikan "Baik". Adapun faktorfaktor yang menyebabkan adalah karena Karyawan sudah bias mencapai target yang ditentukan dalam produktivitas kerja.

\section{b. Meningkatkan Hasil yang Dicapai}

Adapun tanggapan responden mengenai meningkatkan hasil yang dicapai Karyawan PT. Tunggal Perkasa Plantations Air Molek Kabupaten Indragiri Hulu, seperti pada tabel 8 di bawah ini :

Tabel 8: Tanggapan Responden mengenai meningkatkan hasil yang dicapai Karyawan PT. Tunggal Perkasa Plantations Air Molek Kabupaten Indragiri Hulu

\begin{tabular}{|c|l|c|c|c|}
\hline No. & Kategori Jawaban & Bobot & Frekuensi & Nilai Bobot \\
\hline 1. & Sangat Baik & 5 & 27 & 135 \\
\hline 2. & Baik & 4 & 37 & 148 \\
\hline 3. & Cukup Baik & 3 & 20 & 60 \\
\hline 4. & Tidak Baik & 2 & 3 & 6 \\
\hline 5. & Sangat Tidak Baik & 1 & 1 & 1 \\
\hline \multicolumn{2}{|c|}{ Jumlah } & & 90 & 350 \\
\hline
\end{tabular}

Sumber : Data Olahan Hasil Penelitian, Tahun 2019 


$$
\bar{x}=\frac{350}{88}=3,97
$$

Dari tabel di atas, dapat lihat jawaban responden mengenai mengenai meningkatkan hasil yang dicapai Karyawan pada PT. Tunggal Perkasa Plantations Air Molek Kabupaten Indragiri Hulu. Dari responden yang terdiri dari 88 orang yang menyatakan "Sangat Baik" sebanyak 27 orang atau dengan nilai bobot 135. Yang menyatakan "Baik" sebanyak 37 orang atau dengan nilai bobot 148. Yang menyatakan "cukup Baik" sebanyak 20 orang atau dengan nilai bobot 60 , sedangkan yang menyatakan "Tidak Baik" sebanyak 3 orang atau dengan nilai bobot 6 dan yang menyatakan "Sangat Tidak Baik" sebanyak 1 orang atau dengan nilai bobot 1 .

Dari hasil perhitungan rata-rata diperoleh $=3,97$ yang menunjukkan bahwa mengenai meningkatkan hasil yang dicapai Karyawan pada PT. Tunggal Perkasa Plantations Air Molek Kabupaten Indragiri Hulu, dikategorikan "Baik". Adapun faktor-faktor yang menyebabkan adalah karena Karyawan berusaha untuk meningkatkan hasil produktivitas kerja dengan baik.

Berikut rekapitulasi jawaban responden mengenai Produktivitas Tenaga Kerja pada PT. Tunggal Perkasa Plantations Air Molek Kabupaten Indragiri Hulu, seperti pada tabel 9 berikut ini :

Tabel 9: Rekapitulasi Jawaban Responden mengenai Produktivitas Tenaga

Kerja pada PT. Tunggal Perkasa Plantations Air Molek Kabupaten Indragiri Hulu

\begin{tabular}{|c|c|c|c|c|}
\hline No. & Pernyataan dan Jawaban & Frekuensi & Nilai Bobot & Rata-Rata \\
\hline 1. & \begin{tabular}{l} 
Jawaban Responden mengenai \\
Upah Minimum Karyawan pada \\
PT. Tunggal Perkasa \\
Plantations Air Molek \\
a. Sangat Tinggi \\
b. Tinggi \\
c. Cukup Tinggi \\
d. Rendah \\
e. Sangat Rendah \\
\multicolumn{1}{c}{ Jumlah }
\end{tabular} & $\begin{array}{c}29 \\
32 \\
26 \\
1 \\
0 \\
88\end{array}$ & $\begin{array}{c}145 \\
128 \\
78 \\
2 \\
0 \\
354\end{array}$ & $\begin{aligned} \bar{x} & =354 / 88 \\
& =3,96\end{aligned}$ \\
\hline 2. & $\begin{array}{l}\text { Jawaban Responden mengenai } \\
\text { Upah Kerja Lembur Karyawan } \\
\text { pada PT. Tunggal Perkasa } \\
\text { Plantations Air Molek } \\
\text { a. Sangat Tinggi } \\
\text { b. Tinggi } \\
\text { c. Cukup Tinggi } \\
\text { d. Rendah } \\
\text { e. Sangat Rendah }\end{array}$ & $\begin{array}{c}26 \\
30 \\
28 \\
4 \\
0 \\
\end{array}$ & $\begin{array}{c}130 \\
120 \\
84 \\
8 \\
0 \\
\end{array}$ & $\begin{aligned} \bar{x} & =342 / 88 \\
& =3,89\end{aligned}$ \\
\hline & Jumlah & 88 & 342 & \\
\hline 3. & $\begin{array}{l}\text { Jawaban Responden } \\
\text { mengenai Penerangan dalam } \\
\text { lingkungan kerja pada PT. } \\
\text { Tunggal Perkasa Plantations } \\
\text { Air Molek } \\
\text { a. Sangat Baik } \\
\text { b. Baik } \\
\text { c. Cukup Baik } \\
\text { d. Tidak Baik } \\
\text { e. Sangat Tidak Baik }\end{array}$ & $\begin{array}{c}22 \\
40 \\
22 \\
3 \\
1 \\
\end{array}$ & $\begin{array}{c}110 \\
160 \\
66 \\
6 \\
1 \\
\end{array}$ & $\begin{aligned} \bar{x} & =343 / 88 \\
& =3,90\end{aligned}$ \\
\hline & Jumlah & 88 & 343 & \\
\hline
\end{tabular}




\begin{tabular}{|c|c|c|c|c|}
\hline 4. & $\begin{array}{l}\text { Jawaban Responden mengenai } \\
\text { suhu udara lingkungan kerja } \\
\text { pada PT. Tunggal Perkasa } \\
\text { Planations Air Molek } \\
\text { a. Sangat Baik } \\
\text { b. Baik } \\
\text { c. Cukup Baik } \\
\text { d. Tidak Baik } \\
\text { e. Sangat Tidak Baik } \\
\text { Jumlah }\end{array}$ & $\begin{array}{c}23 \\
38 \\
24 \\
2 \\
1 \\
88\end{array}$ & $\begin{array}{c}115 \\
152 \\
72 \\
4 \\
1 \\
344\end{array}$ & $\begin{aligned} \bar{x} & =344 / 88 \\
& =3,91\end{aligned}$ \\
\hline 5. & $\begin{array}{l}\text { Jawaban Responden mengenai } \\
\text { Motivator dalam mengarahkan } \\
\text { Karyawan pada PT. Tunggal } \\
\text { Perkasa Plantations Air Molek } \\
\text { a. Sangat Baik } \\
\text { b. Baik } \\
\text { c. Cukup Baik } \\
\text { d. Tidak Baik } \\
\text { e. Sangat Tidak Baik } \\
\text { Jumlah }\end{array}$ & $\begin{array}{c}23 \\
40 \\
23 \\
2 \\
0 \\
8\end{array}$ & $\begin{array}{c}115 \\
160 \\
69 \\
4 \\
0 \\
348\end{array}$ & $\begin{aligned} \bar{x} & =348 / 88 \\
& =3,95\end{aligned}$ \\
\hline 6. & \begin{tabular}{l} 
Jawaban Responden mengenai \\
Pimpinan menciptakan \\
lingkungan kerja yang baik pada \\
PT. Tunggal Perkasa Plantations \\
Air Molek \\
a. Sangat Baik \\
b. Baik \\
c. Cukup Baik \\
d. Tidak Baik \\
e. Sangat Tidak Baik \\
\multicolumn{1}{c}{ Jumlah }
\end{tabular} & $\begin{array}{c}25 \\
34 \\
26 \\
2 \\
1 \\
88\end{array}$ & $\begin{array}{c}125 \\
136 \\
78 \\
6 \\
0 \\
345\end{array}$ & $\begin{aligned} \bar{x} & =345 / 88 \\
& =3,92\end{aligned}$ \\
\hline 7. & $\begin{array}{l}\text { Jawaban Responden mengenai } \\
\text { kemampuan Karyawan dalam } \\
\text { melaksanakan pekerjaan pada } \\
\text { PT. Tunggal Perkasa Plantations } \\
\text { Air Molek } \\
\text { a. Sangat Baik } \\
\text { b. Baik } \\
\text { c.Cukup Baik } \\
\text { d. Tidak Baik } \\
\text { e. Sangat Tidak Baik } \\
\text { Jumlah }\end{array}$ & $\begin{array}{c}26 \\
32 \\
28 \\
1 \\
1 \\
88\end{array}$ & $\begin{array}{c}130 \\
128 \\
84 \\
2 \\
1 \\
352\end{array}$ & $\begin{aligned} \bar{x} & =352 / 88 \\
& =3,91\end{aligned}$ \\
\hline 8. & \begin{tabular}{l} 
Jawaban Responden mengenai \\
meningkatkan hasil yang \\
dicapai Karyawan pada PT. \\
Tunggal Perkasa Plantations Air \\
Molek \\
a. Sangat Baik \\
b. Baik \\
c. Cukup Baik \\
d. Tidak Baik \\
e. Sangat Tidak Baik \\
\multicolumn{1}{c}{ Jumlah }
\end{tabular} & $\begin{array}{c}27 \\
37 \\
20 \\
3 \\
1 \\
88\end{array}$ & $\begin{array}{c}135 \\
148 \\
60 \\
6 \\
1 \\
350\end{array}$ & $\begin{aligned} \bar{x} & =350 / 88 \\
& =3,97\end{aligned}$ \\
\hline
\end{tabular}


Berdasarkan tabel 9 Rekapitulasi Jawaban Responden mengenai Produktivitas Tenaga Kerja pada PT. Tunggal Perkasa Plantations Air Molek Kabupaten Indragiri Hulu, didapat $=3,92$ dikategorikan "Tinggi / Baik". Adapun faktor-faktor yang menyebabkan adalah karena Karyawan merasa puas dengan upah minimum yang diberikan,Perusahaan menetapkan upah kerja lembur sesuai dengan ketentuan yang ditetapkanPemerintah, tempat kerja sudah dilengkapi dengan fasilitas penerangan yang optimal, suhu udara mendukung guna pencapaian kinerja Karyawan, Pimpinan berusaha memberikan semangat kepada setiap Karyawan dalam mencapai produktivitas kerja, Pimpinan berusaha untuk memberikan kepuasan kepada Karyawan, Karyawan sudah bias mencapai target yang ditentukan dalam produktivitas kerja, Karyawan berusaha untuk meningkatkan hasil produktivitas kerja dengan baik.

\section{PENUTUP}

\section{A. Kesimpulan}

Berdasarkan hasil dan pembahasan penelitian dapat disimpulkan bahawa Produktivitas Tenaga Kerja pada PT. Tunggal Perkasa Plantations Air Molek, dikategorikan Tinggi untuk upah atau Baik untuk lingkungan kerja, Pimpinan, dan produktivitas. Adapun faktor-faktor yang menyebabkannya adalah karena Karyawan merasa puas dengan upah minimum yang diberikan,Perusahaan menetapkan upah kerja lembur sesuai dengan ketentuan yang ditetapkan Pemerintah, tempat kerja sudah dilengkapi dengan fasilitas penerangan yang optimal, suhu udara mendukung guna pencapaian kinerja Karyawan, Pimpinan berusaha memberikan semangat kepada setiap Karyawan dalam mencapai produktivitas kerja, Pimpinan berusaha untuk memberikan kepuasan kepada Karyawan, Karyawan sudah bisa mencapai target yang ditentukan dalam produktivitas kerja, Karyawan berusaha untuk meningkatkan hasil produktivitas kerja dengan baik.

\section{B. Saran}

Untuk lebih meningkatkan Produktivitas Tenaga Kerja pada PT. Tunggal Perkasa Plantations Air Molek perlu adanya pengawasan, insentif yang memuaskan, dan keamanan dalam bekerja serta fasilitas yang sangat memadai.

\section{REFERENCE}

Deliarnov,2000, Motivasi Meraih Sukses, Pustaka Sinar Harapan, Jakarta

Ellizur, Doy, 2004, Evaluasi Pekrjaan, Terjemahan Ny. Rochmulyati Hamzah, Lembaga

Pendidikan dan Pembinaan Manajemen, bekerjasama dengan PT. Pustaka Binaan Prssindo, Jakarta

Gibson, 2000, Motivasi, LP3EES, Jakarta.

Kountzt\&Donnel,2005,Terjemahan Soewarno Handoyoningrat, Pengantar study Ilmu Administrasi dan Manajemen, PT. Gunung Agung, Jakarta

Manullang,2003,Dasar-dasar Manajemen, Penerbit Ghalia Indonesia, Jakarta

Nugroho,2006, Prosfek Keselamatan dan Kesehatan Kerja, UI, Jakarta

Ranupandojo,2001,Sistem Penggajian, PT. Pustaka Binaman Pressindo, Jakarta

Ravianto,2005, Produktivitas dan LabaI, lembaga Sarana Informasi Usaha dan Produktivitas, Jakarta

Soemanto dan Soetopo,2002,Sukses Menjadi Karyawan Profesional, Elek Media Komputindo, Jakarta.

Suprihanto,2002, Motivasi dan Disiplin Kerja Karyawan Untuk Meningkatkan Produktivitas dan Produksi, Produktivitas dan Tenaga Kerja Indonesia

Suwarto, 2001, Manajemen Motivasi, Grasindo, Jakarta 